\title{
DIFFERENCES IN WHOLE BODY VIBRATION EXPOSURES BETWEEN A CAB-OVER AND CONVENTIONAL FLATBED TRUCK
}

\author{
Peter W. Johnson*, Patrik Rynell and Ryan Blood \\ University of Washington \\ Department of Environmental and Occupational Health Sciences
}

\section{Introduction}

Epidemiological studies have shown a relatively strong association between occupational back pain and the exposure to Whole Body Vibration (WBV) with the risks for injury increasing as the duration and dose of WBV increases. Recent research on selfreported musculoskeletal problems amongst professional truck drivers has shown that approximately $60 \%$ of drivers report low back pain. Contributing further the difficulty of quantifying the risk of low back pain from driving occupations is that fact that WBV exposures may vary greatly between vehicle types. Vehicle and seat design have a significant effect on the ability of vibration to travel through the vehicle and reach the operator. Prior research has compared the performance of seat suspensions and their ability to attenuate continuous low frequency and impulsive high frequency WBV exposures. Generally, the major classes of seats which can be installed in vehicles consist of an air suspension, a mechanical suspension, or a solid frame seat with foam and springs as the shock absorbing mechanism. Using a group of experienced truck drivers and calculating time-weight average (TWA) and impulsive WBV exposure parameters, the purpose of this study was to characterize and determine whether there were differences in WBV exposures between a conventional and cab over design flatbed truck.

\section{Methods}

Using a repeated measures design and a standardized test route, WBV exposures were compared when thirteen experienced flatbed truck drivers drove two vehicles, 1) a European-style flatbed truck where the drivers were situated directly over the front wheels (cab-over design) and 2) and a North American-style flatbed truck where the cab was situated behind, rather than over, the front wheels. Both vehicles were analyzed with the stock seats that came with the vehicles, which were solid suspension seats with foam and springs as the only shock absorbing material. The 15 minute standardized test route consisted of a section of freeway and two sections of city streets. A tri-axial seat pad ICP accelerometer (model 356B40; PCB Piezotronics; Depew, NY) was mounted on the driver's seat and the same model accelerometer was securely mounted on the floor of the vehicle. A WBV data acquisition system (model DA-20; RION Co., Ltd.; Tokyo, Japan) was used to collect raw $\left(\mathrm{S}_{\mathrm{ed}}\right)$ and time weighted average vibration exposures $\left(\mathrm{A}_{\mathrm{w}}\right.$, Crest Factor, VDV). The $A_{w}, V D V$, and $S_{\text {ed }}$ values were all normalized to an eight hour day to reflect the drivers' normal work shift. Vehicle speed was collected using a GPS device. Differences in WBV exposures between the trucks were evaluated using paired-t tests and considered significant when $\mathrm{p}$-values were less than 0.05 . 


\section{Results}

Table 1 shows a significant difference in $\mathrm{A}_{\mathrm{w}}, \mathrm{VDV}$, and $\mathrm{S}_{\mathrm{ed}}$ between the cab-over and conventional flatbed truck designs with the cab-over having substantially higher exposures. With respect to exposure limits outlined in ISO $2631-1^{1}$ and $2635-5^{2}$ both the cab-over and conventional truck designs were above the $0.5 \mathrm{~m} / \mathrm{s}^{2}$ action limit for $\mathrm{A}_{\mathrm{w}}$ in the dominant z-axis. The VDV measurements were above the $9.1 \mathrm{~m} / \mathrm{s}^{1.75}$ action level but below the exposure limit $\left(21 \mathrm{~m} / \mathrm{s}^{1.75}\right)$. Finally, the cab-over design $S_{\text {ed }}$ measurements were above the $0.5 \mathrm{MPa}$ action level but below the $0.8 \mathrm{MPa}$ exposure limit while the conventional design truck was below the action limit.

TABLE 1: Mean ( \pm SE) $Z$ axis WBV measures over the whole route by vehicle type [n=13].

\begin{tabular}{|c|c|c|c|c|}
\hline \multirow[b]{2}{*}{ Parameter } & \multicolumn{2}{|c|}{ Vehicle Type } & \multirow[b]{2}{*}{ Difference } & \multirow[b]{2}{*}{ p-value } \\
\hline & Cab-Over & Conventional & & \\
\hline $\mathbf{A}_{\mathrm{w}}(\mathbf{8})\left(\mathrm{m} / \mathrm{s}^{2}\right)$ & $0.75( \pm 0.02)$ & $0.56( \pm 0.02)$ & 0.19 & $<0.0001$ \\
\hline Crest Factor & $8.9( \pm 0.44)$ & $11.5( \pm 0.43)$ & -2.62 & 0.0011 \\
\hline $\operatorname{VDV}(8)\left(\mathrm{m} / \mathrm{s}^{1.75}\right)$ & $16.3( \pm 0.38)$ & $13.4( \pm 0.4)$ & 2.94 & $<0.0001$ \\
\hline $\mathrm{S}_{\text {ed }}(\mathrm{MPa})$ & $0.72( \pm 0.06)$ & $0.48( \pm 0.02)$ & 0.24 & 0.002 \\
\hline Speed $(\mathrm{km} / \mathrm{hr})$ & $54.9( \pm 0.14)$ & $55.4( \pm 0.16)$ & -0.45 & 0.63 \\
\hline
\end{tabular}

\section{Discussion}

The WBV exposure differences between the conventional and cab-over design flatbed trucks showed that the conventional design performed better in attenuating TWA and impulsive exposures. These finding indicate, when selecting vehicles configurations for professional drivers, it may be important that employers consider the differences in WBV exposures between different vehicle options. The results of this study indicated that, relative to vehicles where the cab was situated over the front wheels, vehicles with a cab situated behind the front wheels may decrease occupational WBV exposures. Although the study was conducted in North America, the results may be of interest to the European community which fall under the current European Directive 2002/44/EC ${ }^{3}$. In the future, it would be interesting to evaluate the performance of commercially available seat interventions including semi-active and active vibration dampening seats.

\section{References}

1. International Organization for Standardization. (1997) Mechanical vibration and shockevaluation of human exposure to whole body vibration — part 1: general requirements, ISO 2631-1:1997.

2. International Organization for Standardization. (2004) Mechanical vibration and shockevaluation of human exposure to whole body vibration-part 5: method for evaluating vibration containing multiple shocks, ISO 2631-5:2004.

3. Directive 2002/44/EC of the European Parliament and of the Council of 25 June 2002 . On the minimum health and safety requirements regarding the exposure of workers to the risks arising from physical agents (vibrations). 